\title{
Now, more than ever, our community is needed: spinal cord injury care during a global pandemic
}

\author{
Colleen M. O'Connell ${ }^{1}{ }^{1} \cdot$ Inge Eriks-Hoogland ${ }^{2} \cdot$ James W. Middleton $^{3}$
}

Received: 26 March 2020 / Accepted: 26 March 2020

(c) International Spinal Cord Society 2020

The COVID-19 associated challenges faced by citizens worldwide are experienced more intensely by persons living with spinal cord injury (SCI). The unique medical and mobility concerns of such individuals and their families can often be overlooked in emergencies [1], as catastrophically apparent in disasters such as the earthquake in Haiti 2010 and the hurricane flooding in New Orleans 2005. Global pandemic, while not a sudden-onset disaster, is an emergency, and requires dedicated efforts to mitigate such disproportional impact [2]. Advocacy groups for persons with disability, such as the International Disability Alliance, stress that disabilitybased abandonment or deprioritization for access to health, care and support services is unacceptable and requires a disability-inclusive response to the COVID-19 crisis (http://www.internationaldisabilityalliance.org/covid-19). In several countries, it is being reported that patients with SCI are experiencing limited availability of protective material for health care providers, disruptions in caregiver services and medical supplies [3]. In Washington State, several disability groups have filed a federal complaint with the Department of Health and Human Services against the state's care rationing plans, being fearful about access to essential treatment and equipment, such as ventilators, being denied to persons with disability. The World Health Organization has warned that communities must act to avoid discrimination of persons with disability in such emergency situations, with guidance published to assist providers and governments in ensuring disability-related issues are incorporated into all stages of pandemic response [1].

Colleen M. O'Connell

drcolleenoconnell@horizonnb.ca

1 Dalhousie University Faculty of Medicine, Stan Cassidy Centre for Rehabilitation, Fredericton, NB, Canada

2 Swiss Paraplegic Centre, Nottwill, Switzerland

3 NSW State Spinal Cord Injury Service, Network of the Agency for Clinical Innovation, Sydney, NSW, Australia
As such, the SCI community, including health professionals and advocacy groups, has rapidly come together in a cohesive and responsive manner to proactively mitigate the direct and indirect effects of COVID-19 on our SCI population. Regionally, nationally, and internationally, leaders in SCI have been working collaboratively to address both immediate concerns, such as basic guidance on hand washing, to longer term planning for issues including access to consumable resources (gloves, catheters), caregiver shortages, and implications for discharge planning for inhospital patients with SCI. A rapid pulse survey to generate a global scan of providers on SCI-related issues and cases has been conducted, which will assist in providing information on the current and projected needs. In Canada, a community of SCI stakeholders including clinicians, researchers, and people with lived experience of SCI, rapidly crowdsourced an SCI-specific hand hygiene guide, and through international networks, have moved towards global access with multiple translations available. Globally, the move to incorporation of telehealth/telemedicine for patient care and consultation is an increasingly relevant and viable option, the positive effects of which we might realize long term post pandemic in improving patient access to services.

The COVID-19 outbreak has and will have a direct impact on our rehabilitation services, not only in the acute sector (especially intensive care units) but also as the pandemic progresses, the effects of COVID-19 on both inpatient and community rehabilitation will be faced, including pressure from acute care services to transfer patients to rehabilitation units, and difficulty to provide rehabilitation services in outpatient and home-based settings (due to national and local set restrictions to prevent spreading of the virus). Italy has been one of the countries worldwide confronted with the COVID-19 outbreak. The Italian PMR Society (SIFMER) has published recommendations to ensure appropriate interventions to persons in need of rehabilitation in acute care, inpatient rehabilitation care and outpatient and home-based rehabilitation services [4]. Koh and Hoenig recently published a paper on interventions to 
prevent spreading of the virus in the rehabilitation community [5].

We have the opportunity and responsibility to learn from the experiences of our Italian and other colleagues. How COVID-19 will directly affect persons with SCI is not known yet. Where possible, data on COVID-19 in persons with SCI should be collected in order to learn from the current situation; a detailed data collection initiative on SCI patients with COVID-19 has begun in Italy.

ISCoS through its External Relations Committee has initiated a COVID-19 Task Force/Community of Practice to bring together our Affiliated Societies and Networks, along with other key partner organizations and representatives to facilitate networking and discussion, learn from each other and work together, sharing resources, clinical experiences and strategies, in an effort to improve our health systems preparedness and responses to this evolving Pandemic and assist our patients, colleagues, and SCI community.

Thank you all for taking care of our vulnerable population of people with SCI and please take care of yourselves in the process.
Publisher's note Springer Nature remains neutral with regard to jurisdictional claims in published maps and institutional affiliations.

\section{References}

1. World Health Organization. Guidance note on disability and emergency risk management for health. Geneva: World Health Organization; 2013.

2. Campbell VA, Gilyard JA, Sinclair L, Sternberg T, Kailes JI. Preparing for and responding to pandemic influenza: implications for people with disabilities. Am J Public Health. 2009;99: S294-S300.

3. De Volkskrant. 2020. https://www.volkskrant.nl/nieuws-achtergrond/ ook-in-gehandicaptensector-is-de-nood-hoog babc75a6/.

4. Boldrini P, Bernetti A, Fiore P.SIMFER Executive Committee and SIMFER Committee for international affairs. Impact of COVID-19 outbreak on rehabilitation services and Physical and Rehabilitation Medicine (PRM) physicians' activities in Italy. An official document of the Italian PRM Society (SIMFER). Eur J Phys Rehabil Med. 2020. https://doi.org/10.23736/S1973-9087.20.06256-5.

5. Koh GC-H, Hoenig H. How should the rehabilitation community prepare for 2019-nCoV? Arch Phys Med Rehabil. 2020. https://doi. org/10.1016/j.apmr.2020.03.003. 